\title{
Preparation and Microstuructural Development of Nanocrystalline Titania and Alumina
}

\author{
Ö.Ç. Duvarci, M. Çiftçioğlu, M. Güden and G. Arıkut
}

\author{
Faculty of Engineering, Izmir Institute of Technology, Gülbahçe Köyü Urla-Izmir
}

\author{
Keywords: Titania, Alumina, Nanocrystalline, Sol-Gel, Grain Size
}

\begin{abstract}
The preparation of nanocrystalline titania and alumina was investigated by sol-gel methods using titanium isopropoxide, boehmite and aluminum isopropoxide. Various drying control chemical additives like oxalic acid, acetic acid and polyacrylic acid were used for modifying the drying behaviour and shrinkage of the gels. The sintered densities of the ceramics prepared by sol-gel processing and the dried gels were in the 79-99\% of theoretical density for rutile. The green and sintered densities of the pellets prepared by uniaxial pressing of powders derived from sols, gels and precipitation techniques for titania were in the $40-52 \%$ and $55-83 \%$ respectively. The titania ceramics were observed to experience anatase-rutile phase transformation upon heat treatment at $650^{\circ} \mathrm{C}$. The grain size of the sintered ceramics at $650^{\circ} \mathrm{C}$ was determined to be about $26 \mathrm{~nm}$. Grain size of titania increased to $213 \mathrm{~nm}$. at $850^{\circ} \mathrm{C}$. The mechanical properties of these nanocrystalline ceramics were investigated by using microhardness testing.
\end{abstract}

\section{Introduction}

Ceramics with grain sizes below $100 \mathrm{~nm}$ are known as nanocrystalline ceramics. Nanocrystalline ceramics can have different chemical physical and mechanical properties compared to coarser grained ceramics. They may have a great potential in application related to sensors, catalyst, coating materials, optical devices, pigments, dielectric ceramics, bonding agents, and miniaturization of devices [1,2]. Nanocrystalline ceramics can also have cost reducing properties such as low temperature sintering and superplasticity. Superplasticity can be loosely defined as the ability of a crystalline material to undergo tremendous elongations prior to failure, on the order of hundreds or thousands of percent [3]. Therefore, manufacturing near-net shaped pieces without machining is possible with nanocrystalline ceramics [4,5]. These applications depend on the chemical and physical properties which are affected by the powder synthesis methods. There are various techniques for the preparation of nanocrystalline ceramics. Some of the well-known processes are: plasma synthesis, chemical vapor deposition and sol-gel synthesis. Among them, the sol gel synthesis is a powerful method for the design of new materials based on the hydrolysis and condensation reactions of molecular precursors such as metal alkoxides[6].

In this work, we have tried to find new approaches to prepare bulk nanocrystalline titania and alumina ceramics by sol gel synthesis and investigated the influence of synthesis conditions on microstructure.

\section{Experimental}

Titania and alumina ceramics were prepared from titanium (IV) isopropoxide (Aldrich, 97\%), aluminium isopropoxide (Aldrich, 98\%) and Boehimite precursor (Sasol). The molar ratio of the reactants for the preparation of titania sol was $\mathrm{Ti}\left[\mathrm{OC}\left(\mathrm{CH}_{3}\right)_{2}\right]_{4}: \mathrm{HNO}_{3}: \mathrm{H}_{2} \mathrm{O}: \mathrm{CH}_{3} \mathrm{CH}(\mathrm{OH}) \mathrm{CH}_{3}$ $=1: 0.0537: 2: 20$. Predetermined amounts of titanium (IV) isopropoxide were diluted with half of the required amount of 2-propanol. 1.44 M nitric acid solution was mixed with the rest of the total 2propanol. The acid-alcohol solution was added to the alkoxide-alcohol solution slowly while the mixture was stirred vigorously with a magnetic stirrer. The sol $(\mathrm{pH}=3.09)$ gelled in $3-4$ days at room temperature. Gels were then dried at $40^{\circ} \mathrm{C}$ in a vacuum oven. In order to reduce the extent of cracking of the gels, some DCCA's (Oxalic acid, acetic acid, and polyacrylic acid) were introduced into the sols in 1-2 wt- $\%$ solids concentrations. Powder A was prepared from titania gels dried at 
$175^{\circ} \mathrm{C}$ for about 10 hours and subsequently ground in a mortar followed by ball milling in an alcoholic medium for 12 hours. This suspension was ultrasonically treated for five hours and subsequently dried at $70^{\circ} \mathrm{C}$. Powder $\mathrm{B}$ was prepared by the precipitation of the sol in a large quantity of water. Precipitation occurred simultaneously and the precipitate was separated by centrifugation, further dried at $70^{\circ} \mathrm{C}$ and subsequently ground in a mortar. Powder $\mathrm{C}$ was prepared by drying the gel at $80^{\circ} \mathrm{C}$ for ten hours, ball milled for 12 hours in an alcoholic medium and dried at a temperature of $110^{\circ} \mathrm{C}$ for 15 hours. The calcination of the powders were carried out at $400^{\circ} \mathrm{C}$ for two hours. Aluminum isopropoxide was hydrolyzed at $80^{\circ} \mathrm{C}$ for 3 hours peptised with appropriate amounts of acid to form a stable colloidal solution and was kept at about $80^{\circ} \mathrm{C}$ under vigorous stirring. The molar ratio the reactants was $\mathrm{Al}\left[\mathrm{OC}\left(\mathrm{CH}_{3}\right)_{2}\right]_{4}: \mathrm{HNO}_{3}: \mathrm{H}_{2} \mathrm{O}=1: 0.25: 100$. The sol was dried at room temperature and subsequently ground by ball mill for 2 hours.

Green pellets were prepared by uniaxial dry pressing in a $10 \mathrm{~mm}$. diameter die to a final thickness of about $1 \mathrm{~mm}$. at $304 \mathrm{MPa}$. Titania gels and pellets were air sintered at 650, 700, 750, 800 and $850^{\circ} \mathrm{C}$ for two hours (Carbolite $1600 \mathrm{RHF}$ ) with $10^{\circ} \mathrm{C} / \mathrm{min}$. heating rate for two hours. The final density of the sintered samples were determined by using Archimedes' method (Sartorius YD01). The samples were characterized by using TGA-51/51H, Shimadzu Co., by Vickers Micro-Hardness Tester (HVS-1000), X Ray diffractometer Philips 'XPERT Pro and SEM Philips XL 30S FEG.

\section{Results and Discussion}

Significant shrinkage was observed during drying of the titania gels because of low sol solids content (about $6 \mathrm{wt}-\%$ ). Most gels cracked during the slow solvent removal process. The addition of $1 \mathrm{wt}-\%$ polyacrylic acid caused faster gelation and gelation occurred in 1-2 days. Formation of blurry sols and very fast gelation were observed when polyacrylic acid was added at $2 \mathrm{wt}-\%$ levels. The use of oxalic acid at $1 \mathrm{wt}-\%$ level didn't affect the gelation time but 2 wt- $\%$ addition caused gelation in 2 days. Acetic acid additions didn't affect sol clarity and the gelation time at 1-2 wt $\%$ levels.
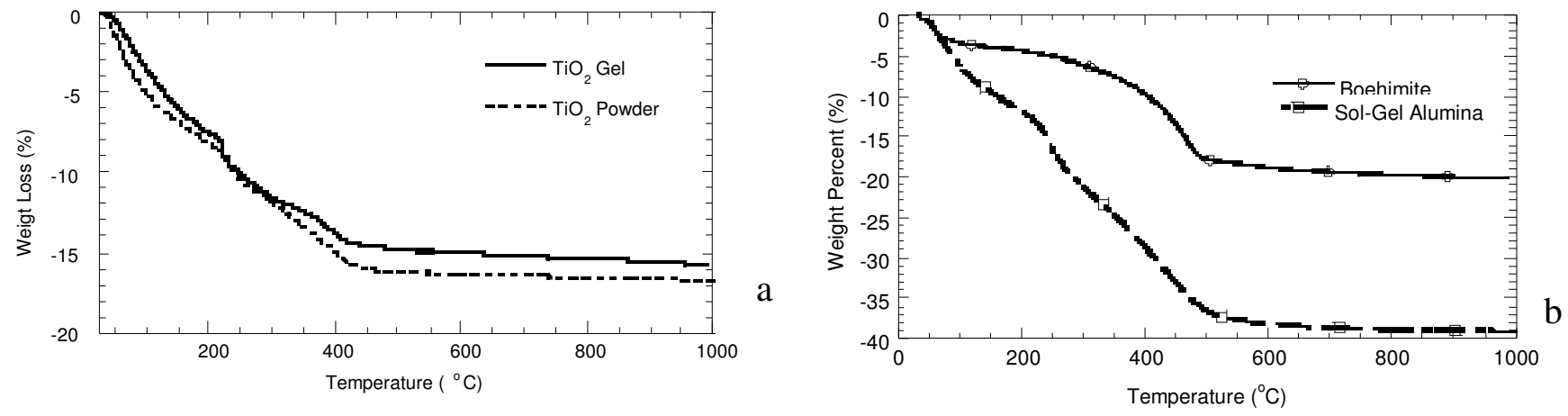

Fig.1. TGA curves of the Titania (a) and Alumina (b) samples.

TGA curves of the titania gel without DCCA's and powder A is shown in Fig.1-a. Total weight loss about $15 \%$ was observed at around $400^{\circ} \mathrm{C}$. This steady weight loss may be due to the removal residual alcohol and organics from the samples. The powder calcination temperature was chosen as $400^{\circ} \mathrm{C}$ for titania. The total weight losses of sol-gel derived alumina and boehimite are about $37 \%$ and $20 \%$ respectively at about $500^{\circ} \mathrm{C}$. The calcination temperature was chosen as about $500^{\circ} \mathrm{C}$. The densification behavior of dried gels and powder pellets is shown in Fig.2. The green densities of Powder A pellets were in the $49-53 \%$ of theoretical density range (theoretical density of rutile was taken as $4.21 \mathrm{~g} / \mathrm{cm}^{3}$ ). The sintered density increased to $55 \%$ and $72 \%$ at $650^{\circ} \mathrm{C}$ and $850^{\circ} \mathrm{C}$ with significant levels of open and closed porosity $\left(14.39 \%\right.$ and $30.61 \%$ at $650^{\circ} \mathrm{C}, 10.11 \%$ and $17.39 \%$ at $850^{\circ} \mathrm{C}$ respectively). The green body densities of powders $\mathrm{B}$ and $\mathrm{C}$ were in the $41-46 \%$ and $49-52 \%$ ranges respectively. The sintered density of the precipitation derived powder B increased steadily with respect to temperature to $82 \%$ of theoretical density at $850^{\circ} \mathrm{C}(13.1 \%$ open porosity and $4.9 \%$ closed porosity). The use of ultrasonic treatment, the gel drying temperature and sol precipitation all seem to have affects on the sintering behavior of those powders. The sintered densities of dried gel 
pieces were above $88 \%$ of theoretical density at $650^{\circ} \mathrm{C}$. The addition of DCCA's as shown in Fig. 2 generally improved the final sintered densities.

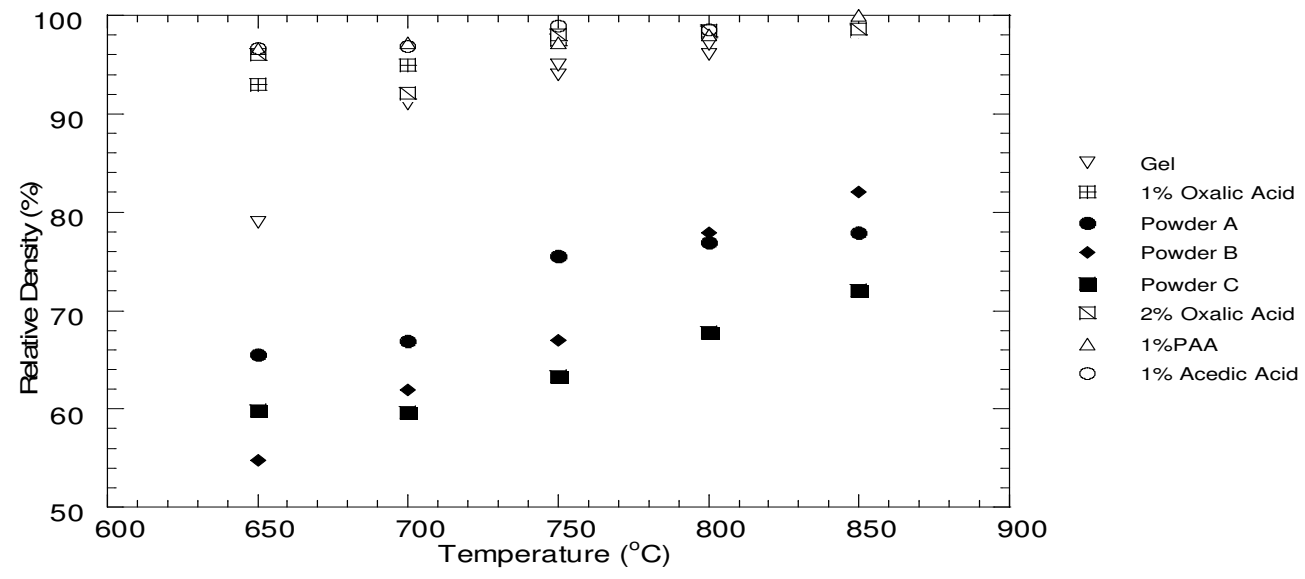

Fig.2. Sintering behavior of Route A, B, C, the gels with and without DCCAs.

According to the XRD data, calcined titania samples were in anatase form, and anatase-rutile transformation occurs at $650^{\circ} \mathrm{C}$ and was totally rutile at $700^{\circ} \mathrm{C}$. Boehmite transformed into $\gamma$ Alumina at $500^{\circ} \mathrm{C}$ and was stable up to $900^{\circ} \mathrm{C}$ and $\alpha$-alumina was the dominant phase at $1200^{\circ} \mathrm{C}$.
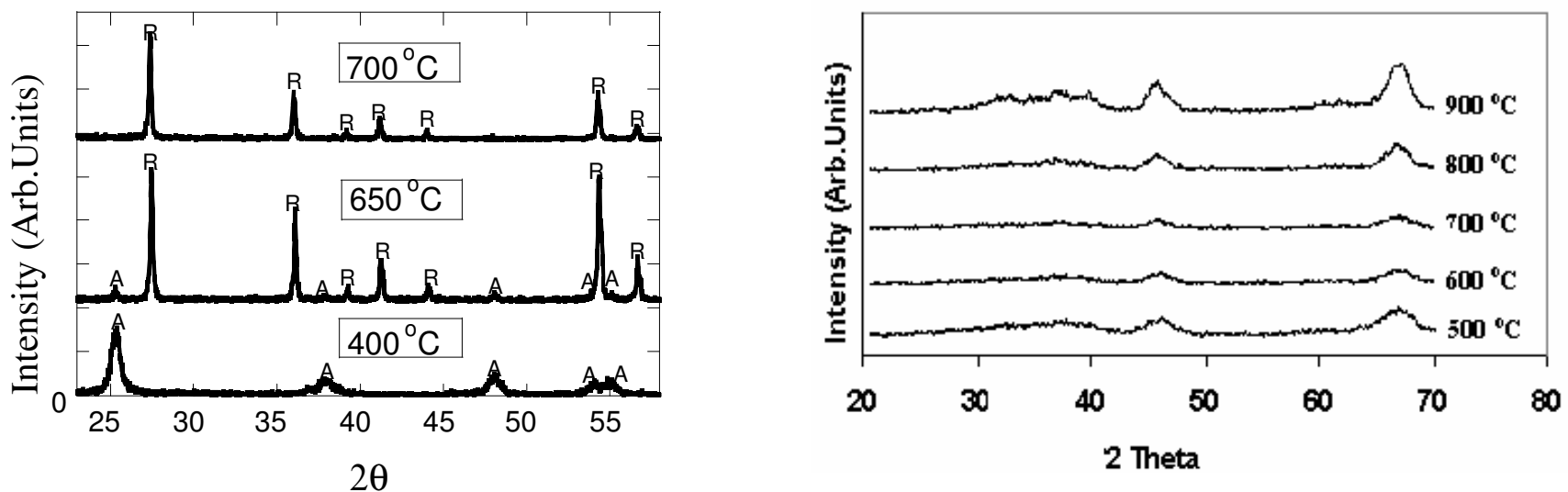

Fig. 3.XRD diffraction pattern of (a) Titania and (b) Alumina sintered at various temperatures.
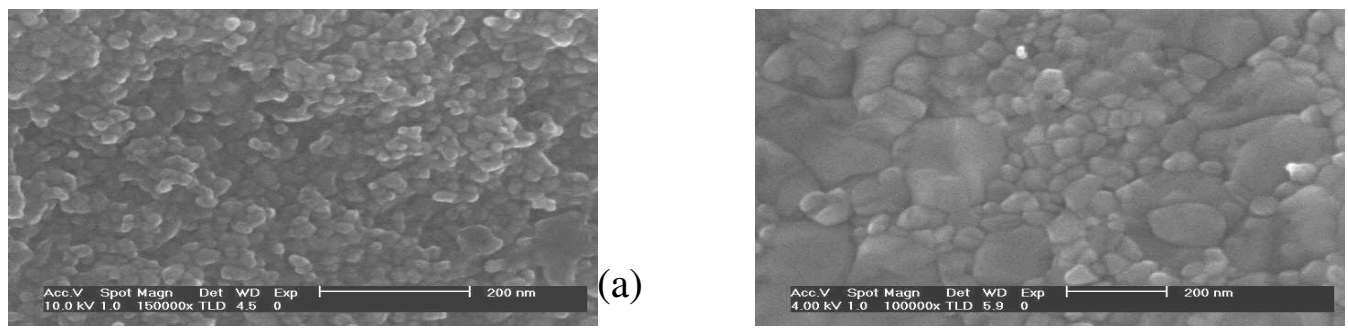

(b)

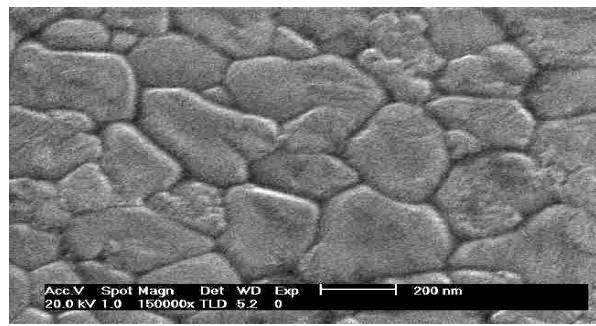

(c)

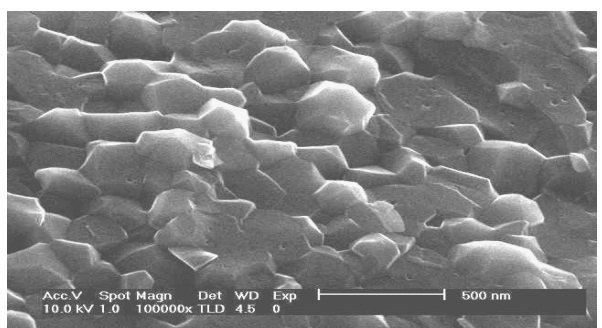

(d)

Fig.4. SEM micrographs of Titania Samples sintered at (a)650, (b)700, (c)750, (d)850. 
The grain size of the titania samples sintered at $650^{\circ} \mathrm{C}$ was uniform with a grain size of about 25 $\mathrm{nm}$. as seen in fig. 5. The grain size increased from $51 \mathrm{~nm}$. to $208 \mathrm{~nm}$. (Fig. 6), when the samples sintered at 700 and $850^{\circ} \mathrm{C}$. For the titania sintered at $700^{\circ} \mathrm{C}$ showed non-uniform grain size distribution, most probably due to the anatase-rutile transformation.

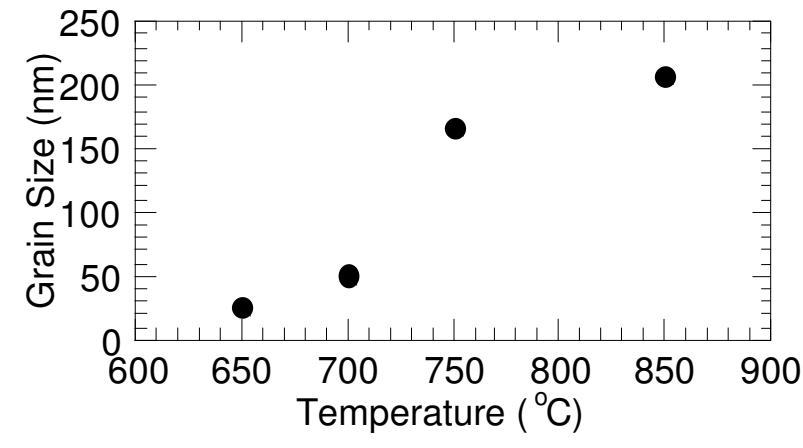

Fig.5. Grain size distribution of titania sintered at $650,750,850^{\circ} \mathrm{C}$.

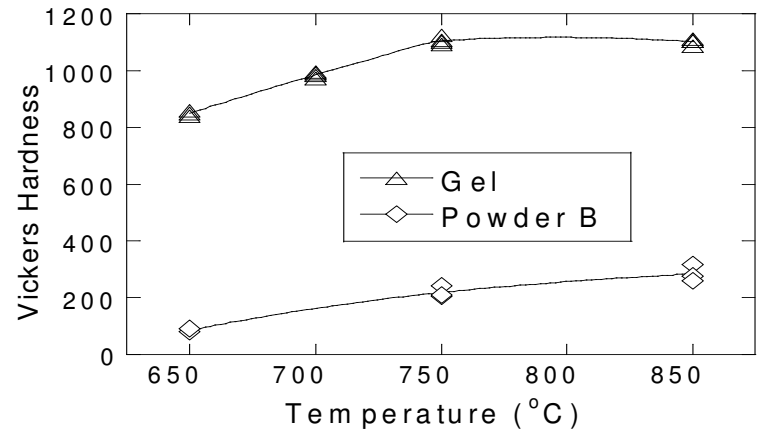

Fig.6. Hardness vs. temperature for titania samples.

The Vickers hardness test results of the sintered gel and powder B pellets are shown as a function of sintering temperature in Fig. 7. The hardness of the sintered gels increased until $750^{\circ} \mathrm{C}$ remained almost constant between $750-850^{\circ} \mathrm{C}$, which is in agreement with the sintering behavior of the gels given in Fig. 2.

\section{Summary}

Nanocrystalline titania ceramics were prepared from sol-gel derived powders the gels in the 650$850^{\circ} \mathrm{C}$ sintering range. The powder pellets compacted at $300 \mathrm{MPa}$ had lower densities than the gels. The gels mostly fractured into several pieces during drying. The extent of gel cracking was reduced with the addition of 1-2\% PAA, acetic acid and oxalic acid to the sols. High relative sintered densities for the gels $(>90 \%)$ were obtained at $650^{\circ} \mathrm{C}$. The XRD patterns showed that titania transformed from anatase to rutile at $650^{\circ} \mathrm{C}$ and alumina transforms from boehmite to $\gamma$-Alumina at $500^{\circ} \mathrm{C}$. The grain size of the titania samples was $26 \mathrm{~nm}$ at $650^{\circ} \mathrm{C}$ and it increased to $213 \mathrm{~nm}$ at $850^{\circ} \mathrm{C}$. The vicker's hardness of the gel derived titania ceramics was about $1000 \mathrm{MPa}$.

\section{References}

[1] Kim H.G. and Kim K.T. Densification behavior of nanocrystalline titania powder compact under high temperature, acta Materilia Vol. 47, No. 13 (1999), p.3561

[2] Minimani T. And Patil K.C., Solution combustion synthesis of nanoscale oxides and their composites, Mater. Phys. Mech. 4, (2001), p. 134

[3] Mayo M.J., High and low temperature superplasticity inNanocrystalline materials, NanoStmctured Materials, Vol. 9. (1997) p. 717

[4] Mayo M.J., Hague D.C., Using superplastic flow to process nanocrystalline ceramics, The Minerals, Metal and Materials Society (1997), p. 31

[5] Mayo M.J., Hague D.C., Chen D.-J., Processing nanocrystalline ceramics for applications in superplaticity, Materials Science and Engineering A166 (1993), p. 145

[6] Mackenzie, J.D.,Sol-Gel Research-Achievements Since 1981 and Prospects for the Future, Journal of Sol-Gel Science and Technology 26 (2003), p. 23 